\title{
Keragaan Pertumbuhan dan Hasil Enam Belas Genotipe Tomat (Solanum lycopersicum L.) di Dataran Rendah
}

\author{
The Growth and Yield of Sixteen Tomato (Solanum lycopersicum L.) \\ Genotypes Grown in Lowlands \\ Santi K. Pardosi, Rustikawati", Dotti Suryati \\ Program Studi Agroekoteknologi, Fakultas Pertanian, Universitas Bengkulu \\ *: tika_ngrh@yahoo.com
}

\begin{abstract}
Tomato is a high nutritional value fruit vegetables. Genetic variation is valuable plant breeding material which can be measured in terms of yield potential. This study aimed to compare the growth and yield components of 16 tomato genotypes in the lowlands. The experiment was conducted in Medan Baru Experimental Station of, Faculty of Agriculture, University of Bengkulu, with the elevation of $10 \mathrm{~m}$ above sea level. This was performed from September 2013 to January 2014. The experiment was set in a completely randomized design with a single factor of 16 tomato genotypes with 3 replications acounting to 48 experimental units, each of which consisted of 2 plants. The sixteen genotypes tested were Mirah, Berlian, CIN 06, SU, Kudamati 3, Lombok 3, Lombok 4, Makassar, Aceh 3, Aceh 5, Ranti Situbondo, Ranti, Situbondo Gelombang, Situbondo, Kemir, Meranti 2, Gondol Lonjong. There were significant differences in plant height, stem diameter, number of leaves, stomatal density, flowering age, harvest age, fruit diameter, fruit sweetness, fruit hardness, total fruit weight, fresh weight, and dry weight. Based on total fruit weight. The genotypes potentially cultivated in the lowlands are Ranti, Situbondo Gelombang, Kudamati 3, Situbondo, and Makassar.
\end{abstract}

Keywords: genotype, tomato, lowland

\begin{abstract}
ABSTRAK
Tomat merupakan salah satu komoditas sayuran buah yang memiliki nilai gizi dan ekonomi tinggi. Variasi genetik sebagai materi pemuliaan tanaman dapat diukur dari segi potensi hasil. Penelitian ini bertujuan untuk membandingkan keragaan pertumbuhan dan komponen hasil 16 genotipe tomat di dataran rendah. Kegiatan penelitian dilaksanakan bulan September 2013 hingga Januari 2014 di kebun Percobaan Laboratorium Agronomi, Fakultas Pertanian, Universitas Bengkulu. Ketinggian lokasi penelitian adalah $10 \mathrm{~m}$ diatas permukaan laut. Penelitian menggunakan rancangan acak lengkap dengan faktor tunggal yaitu 16 genotipe tomat dengan 3 ulangan sehingga terdapat 48 unit percobaan. Setiap unit percobaan terdapat 2 tanaman. Enam belas genotipe yang diuji adalah Mirah, Berlian, CIN 06, SU, Kudamati 3, Lombok 3 , Lombok 4, Makassar, Aceh 3, Aceh 5, Ranti Situbondo, Ranti S. Gelombang, Situbondo, Kemir, Meranti 2, Gondol Lonjong. Dari 16 genotipe tomat yang diuji terdapat perbedaaan nyata pada tinggi tanaman, diameter batang, jumlah daun, kerapatan stomata, umur berbunga, umur panen, diameter buah, kemanisan buah, kekerasan buah, bobot buah total, bobot segar brangkasan, dan bobot kering brangkasan. Berdasarkan bobot buah total, genotipe yang berpotensi dibudidayakan di dataran rendah adalah Ranti S. Gelombang, Kudamati 3, Situbondo, dan Makassar.
\end{abstract}

Kata kunci : genotipe, tomat, dataran rendah 


\section{PENDAHULUAN}

Tomat (Solanum lycopersicum L.) merupakan tanaman semusim berbentuk perdu dan termasuk ke dalam famili solanaceae. Buahnya merupakan sumber vitamin dan mineral. Tomat dikonsumsi sebagai buah segar, bumbu masakan atau diolah lebih lanjut sebagai bahan baku industri makanan seperti sari buah dan saus tomat (Wasonowati, 2011). Tomat mengandung zat lycopen yang tinggi. Lycopen merupakan pigmen yang menyebabkan tomat berwarna merah. Seperti halnya betakaroten, lycopen termasuk ke dalam golongan karotenoid. Zat lycopen berkhasiat untuk mencegah dan mengobati berbagai macam penyakit seperti kanker paru-paru, kanker prostat, kanker rahim, tumor pankreas dan tumor tenggorokan (Cahyono, 2008).

Badan Pusat Statistik (2012) mengatakan bahwa produksi nasional tomat tahun 2010 adalah sebesar 891.616 ton sedangkan pada tahun 2011 produksi tomat meningkat menjadi 954.046 ton. Pada tahun 2012 produksi tomat di Indonesia berkurang 66.490 ton menjadi 887.556 ton. Purwati (2009) mengatakan bahwa daerah sentra produksi tomat meliputi Provinsi Jawa Barat dengan luas area penanaman 11.904 ha, Sulawesi selatan (5.681 ha), Sumatera Utara (4.136 ha) dan Bengkulu (3.687 ha). Penyebab turunnya produksi tomat di Indonesia diantaranya karena ketersediaan varietas unggul dan mutu benih yang rendah. Selain itu, pengembangan varietas berdaya hasil tinggi hanya cocok di dataran tinggi. Serangan penyakit layu fusarium juga dapat mengurangi produksi tomat hingga $30 \%$, bahkan pada musim penghujan dapat mencapai 60\% (Purwati, 2007).

Produksi tomat di dataran rendah sangat kecil karena suhu tinggi dan serbuk sari bunga mudah rontok. Jones (2008) menyatakan bahwa terdapat berbagai kendala dalam budidaya tomat di dataran rendah, antara lain : (1) Kesesuaian iklim. Tomat tumbuh baik pada temperatur antara $18,3^{\circ} \mathrm{C}-32,2^{\circ} \mathrm{C}$ dengan kelembaban udara sekitar 95\%, (2) Kualitas Buah. Tomat yang ideal memiliki ukuran yang seragam, warna buah merata, berdaging buah tebal dan cukup keras, serta tinggi akan kandungan nutrisi, (3) Ketahanan terhadap hama dan penyakit. Dataran rendah mempunyai curah hujan dan temperatur yang tinggi sehingga tanaman tomat rentan terhadap serangan penyakit layu bakteri ( $P s e-$ udomonas solanacearum), sehingga hasil buahnya akan rendah (Villareal, 1980).

Salah satu upaya yang dapat dilakukan untuk memperoleh varietas yang dapat dibudidayakan di dataran rendah adalah dengan merakit varietas tomat adaptif di dataran rendah. Ambarita et al. (2009) menyatakan bahwa perakitan varietas baru diarahkan untuk meningkatkan potensi hasil dan mutu produk sehingga varietas baru mempunyai daya kompetitif tinggi. Selain itu, perakitan varietas baru tetap penting untuk meningkatkan variasi genetik yang dapat menjadi materi pemuliaan tanaman. Oleh sebab itu, diperlukan plasma nutfah sebagai sumber gen adaptif terhadap dataran rendah. Dalam rangka perakitan kultivar tersebut berbagai aksesi tomat lokal telah dikoleksi dari beberapa provinsi di Indonesia.

Tujuan penelitian ini adalah membandingkan keragaan dan menapis 16 genotipe tomat yang adaptif dataran rendah.

\section{METODE PENELITIAN}

\section{Pelaksanaan Penelitian}

Penelitian dilaksanakan pada bulan September 2013 sampai Januari 2014 di kebun Percobaan Laboratorium Agronomi, Fakultas Pertanian, Universitas Bengkulu. Ketinggian lokasi penelitian adalah $10 \mathrm{~m}$ diatas permukaan laut. Penelitian ini menggunakan rancangan acak lengkap dengan 
faktor tunggal yaitu 16 genotipe tomat dengan 3 ulangan sehingga terdapat 48 unit percobaan. Setiap unit percobaan terdapat 2 tanaman. Enam belas genotipe yang diuji adalah Mirah, Berlian, CIN 06, SU, Kudamati 3, Lombok 3, Lombok 4, Makassar, Aceh 3, Aceh 5, Ranti Situbondo, Ranti S. Gelombang, Situbondo, Kemir, Meranti 2, Gondol Lonjong.

\section{Tahapan Penelitian}

Pembibitan tomat dilakukan pada tray dengan ukuran $54 \mathrm{~cm}$ x $28 \mathrm{~cm}$ yang berisi 50 lubang tanam. Media untuk pembibitan berisi campuran tanah dan pupuk kompos dengan perbandingan $1: 1$. Setiap lubang tanam diisi 2 benih tomat dan ditanamkan dengan kedalaman $1 \mathrm{~cm}$. Pemeliharaan bibit dilakukan secara intensif. Penyiraman dilakukan 2 kali sehari yaitu pagi dan sore hari dengan menggunakan gembor agar tidak merusak bibit tanaman. Penyemprotan fungisida dengan bahan aktif mankozeb $80 \%$ konsentrasi $2 \mathrm{~g}$ liter $^{-1}$ air untuk mengendalikan jamur dan insektisida berbahan aktif deltamethrin dengan konsentrasi 2,5 $\mathrm{g}$ liter $^{-1}$ air untuk menghindari serangan organisme pengganggu tanaman. Setelah bibit berumur 30 hari atau telah muncul 5 helai daun bibit dipindahkan ke polibag.

Sebelum tanaman dipindah, media tanam di polibag disiram terlebih dahulu. Penanaman dilaksanakan dengan menempatkan tanaman pada polibag yang telah diisi dengan media tanam berupa tanah, pupuk kandang dan sekam dengan perbandingan 2 $: 1: 1$. Setiap polibag berisi $10 \mathrm{~kg}$ media tanam. Pupuk yang diberikan adalah urea 200 $\mathrm{kg} \mathrm{Ha}^{-1}$ (setara dengan 7,5 g/tan) yang diberikan setengah dosis saat tanam dan setengah sisanya diberikan 3 MST. Pupuk SP36 $200 \mathrm{~kg}$. $\mathrm{Ha}^{-1}$ (setara dengan 7,5 g/tan) dan $\mathrm{KCl} 100 \mathrm{~kg}$. Ha ${ }^{-1}$ (setara dengan 3,75 g/tan) yang diberikan saat tanam. Cara pemberian pupuk dengan alur melingkar sedalam $3 \mathrm{~cm}$ dan jarak $10 \mathrm{~cm}$ dari pangkal batang.
Pemeliharaan tanaman meliputi penyulaman, penyiraman, pembuangan tunas air, pengajiran, pengendalian gulma, serta pengendalian hama dan penyakit. Penyulaman tanaman dilakukan 1 minggu pada tanaman yang menunjukkan pertumbuhan yang layu, terserang hama penyakit atau mati.

Penyiraman dilaksanakan jika tidak turun hujan yang dilakukan dua kali sehari pada pagi hari dan sore hari. Penyiraman dilakukan dengan cara menyiramkan air pada polibag sebanyak lebih kurang $1 \mathrm{~L}$.

Pembuangan tunas air dilakukan dengan membuang tunas-tunas yang keluar dari ketiak daun agar tidak menjadi cabang. Tujuan pembuangan tunas air adalah untuk mengurangi jumlah tunas sehingga merangsang pertumbuhan generatif, meningkatkan penerimaan sinar matahari dan keseragaman ukuran buah. Pembuangan tunas air dilakukan pada pagi hari agar luka bekas yang dipangkas cepat kering dengan cara dirempel.

Pengajiran tanaman dilakukan 5 minggu setelah tanam agar tanaman tidak rebah. Ajir terbuat dari bambu dengan panjang 100-150 cm. Ajir dipasang dengan jarak $10 \mathrm{~cm}$ dari tanaman tomat. Selanjutnya diikat dengan model angka 8 sehingga tidak terjadi gesekan antara batang tomat dengan ajir yang dapat menimbulkan luka.

Pengendalian gulma dilakukan secara manual dengan mencabuti gulma-gulma yang tumbuh di sekitar pertanaman di dalam polibag sedangkan di luar polibag dengan menyemprotkan herbisida yang memiliki bahan aktif parakuat diklorida dengan konsentrasi $276 \mathrm{~g}$ liter $^{-1}$. Gulma yang tumbuh harus disiangi agar tidak menjadi pesaing dalam menyerap unsur hara. Gulma yang terlalu banyak akan mengurangi unsur hara sehingga tanaman tomat menjadi kerdil dan menjadi sarang hama penyakit.

Pengendalian hama dan penyakit tanaman dilakukan secara kimiawi dengan me- 
nyemprotkan insektisida yang memiliki bahan aktif deltamethrin konsentrasi 2,5 $\mathrm{g} \mathrm{liter}^{-1}$ air, fungisida berbahan aktif mankozeb $80 \%$ dengan konsentrasi $2 \mathrm{~g}$ liter $^{-1}$ air dan bakterisida berbahan aktif streptomisin sulfat konsentrasi $2 \mathrm{~g}$ liter $^{-1}$. Pengendalian hama dan penyakit dilakukan dengan interval 1-2 kali seminggu bergantung intensitas serangan.

Pemanenan dilakukan pada buah yang telah menunjukkan kriteria masak fisiologis dengan ciri, kulit buah mengalami perubahan dari warna hijau menjadi kekuning-kuningan. Pemanenan dilakukan pada pagi atau sore hari di saat cuaca cerah. Buah dipetik hingga tangkai buah terputus. Pemanenan buah dilakukan satu-persatu dan dipilih buah yang siap petik.

\section{Variabel yang diamati}

Tinggi tanaman $(\mathrm{cm})$, diameter batang (mm), jumlah daun, tingkat kehijauan daun, kerapatan stomata $\left(\mathrm{mm}^{2}\right)$, umur berbunga (hst), umur panen (hst), diameter buah (mm), kemanisan buah (brix), kekerasan buah $\left(\mathrm{Kgf} / \mathrm{cm}^{2}\right)$, bobot per buah $(\mathrm{g})$, bobot buah total per tanaman (g), bobot segar brangkasan (g), bobot kering brangkasan $(\mathrm{g})$.

\section{Analisis Data}

Data yang diperoleh dari hasil pengamatan dianalisis secara statistik menggunakan analisis varians (uji F) pada taraf $5 \%$ dan jika terdapat perbedaan yang nyata maka dilanjutkan uji beda rata-rata Duncan's Multiple Range Test (DMRT) pada taraf $5 \%$ untuk membandingkan rata-rata antar genotipe.

\section{HASIL DAN PEMBAHASAN}

\section{Kondisi Umum Penelitian}

Kondisi iklim selama penelitian tidak cukup sesuai untuk pertumbuhan tanaman tomat. Rata-rata curah hujan sela- ma penelitian dari bulan September 2013 sampai Januari 2014 sebesar 479,04 mm bulan $^{-1}$. Suhu rata-rata saat penelitian yaitu $27,04{ }^{\circ} \mathrm{C}$ sedangkan kelembaban rata-rata yaitu $84,2 \%$ (Lampiran 1). Menurut Fitriani (2012) bahwa tanaman tomat tumbuh optimal pada curah hujan 750-1.250 mm tahun $^{-1}$, suhu $18-29{ }^{\circ} \mathrm{C}$ dan kelembaban $80 \%$. Curah hujan, suhu dan kelembaban merupakan faktor yang sangat berpengaruh terhadap pertumbuhan dan hasil tanaman tomat.

Pada umur satu minggu setelah tanam, genotipe tomat terserang penyakit busuk leher akar atau busuk pangkal batang diduga disebabkan oleh jamur Rhizoctonia solani. Tomat yang terserang adalah genotipe Kudamati 3 pada ulangan 1 dan Ranti Situbondo pada ulangan 2. Prihantoko (2006) mengatakan bahwa tanaman tomat yang diberi $R$. solani mengalami kebusukan dan batang menjadi keriput. Serangan ini mengakibatkan translokasi hara dan air di dalam jaringan tanaman menjadi terhambat. Pengendalian dilakukan secara manual dengan mencabut tanaman yang terserang penyakit agar tanaman yang lain tidak menular dan langsung dilakukan penyulaman.

Pada pertumbuhan fase vegetatif, penampilan tanaman tomat secara keseluruhan terlihat baik dari segi persentase tumbuh. Sementara, pada fase generatif tanaman tomat mulai terserang penyakit layu bakteri diduga disebabkan oleh Pseudomonas solanacearum. Adanya penyakit layu bakteri diduga karena tanah yang digunakan sebagai media tanam telah mengandung penyakit layu bakteri. Genotipe tanaman yang terserang yaitu Aceh 3, Meranti 2, dan Gondol Lonjong. Gejala serangan penyakit layu bakteri ditandai dengan adanya daun yang layu dimulai dengan daun yang muda kemudian berlanjut pada seluruh bagian tanaman. Serangan mulai nampak pada waktu tanaman berumur 6 minggu setelah tanam (MST). Pengendalian terhadap penyakit tanaman layu bakteri di- 
lakukan secara manual dan kimiawi. Secara manual dilakukan dengan mencabut tanaman yang terserang sedangkan pengendalian secara kimiawi menggunakan bakterisida berbahan aktif streptomisin sulfat dengan konsentrasi $2 \mathrm{~g} \mathrm{liter}^{-1}$ air dengan cara menyiramkan larutan bakterisida ke media tanam.

\section{Analisis Genotipe Tomat}

Analisis varians dilakukan untuk mengetahui perbedaan antar genotipe pada variabel yang diamati. Terdapat perbedaan yang nyata antar genotipe pada variabel tinggi tanaman, diameter batang, jumlah daun, kerapatan stomata, dan umur berbunga. Pada variabel tingkat kehijauan daun menunjukkan berbeda tidak nyata (Tabel 1).

Berdasarkan hasil uji F pada taraf 5\% variabel umur panen, diameter buah, kemanisan buah, kekerasan buah, bobot buah total per tanaman, bobot segar brangkasan, dan bobot kering brangkasan berbeda nyata antar genotipe. Berbeda dengan variabel bobot per buah yang berbeda tidak nyata antar genotipe (Tabel 2).

Pertumbuhan Vegetatif Genotipe Tomat

Variabel pengamatan yang berbeda nyata dilakukan uji lanjut menggunakan Duncan's Multiple Range Test (DMRT) pada taraf $5 \%$, yang disajikan pada Tabel 3 berikut :

\section{Tinggi Tanaman}

Uji lanjut DMRT memperlihatkan bahwa tinggi tanaman antar genotipe yang diuji berbeda secara nyata (Tabel 3). Genotipe Meranti 2 dan Aceh 5 berbeda tidak nyata dengan genotipe Situbondo, Gondol Lonjong, Lombok 4, dan CIN 06 tetapi berbeda nyata dengan genotipe lainnya. Genotipe yang paling rendah pertumbuhan tingginya genotipe SU dengan tinggi 33,86 cm. Hasil penelitian Suryadi et al. (2004), berdasarkan uji lanjut Scott-Knott pada tomat yang diteliti dapat dibedakan ke dalam dua kelompok, kelompok pertama tinggi tanaman 46,0-48,2 cm, kelompok kedua dengan tinggi tanaman 59,7-80,0 cm. Sutapradja (2008) memperoleh data tinggi kultivar Mutiara 68,8 cm berbeda nyata dengan kultivar Intan yang hanya mencapai tinggi 46,4 cm. Nazirwan et al. (2014) menyatakan bahwa perbedaan tinggi tanaman dipengaruhi oleh faktor genetik dari masing-masing galur/nomor dan lingkungan seperti intensitas cahaya, temperatur dan ketersediaan unsur hara.

\section{Diameter Batang}

Diameter batang genotipe Makassar adalah satu-satunya genotipe yang paling besar $(10,02 \mathrm{~mm})$ dan berbeda nyata dengan genotipe lainnya. Genotipe yang memiliki diameter batang terkecil terdapat pada genotipe SU dengan nilai $6,35 \mathrm{~mm}$ (Tabel 3). Menurut Widiyastiningsih et al. (2012) pertambahan ukuran tubuh tanaman mengakibatkan pertambahan jaringan sel yang dihasilkan oleh pertambahan ukuran sel.

\section{Jumlah Daun}

Jumlah daun pada enam belas genotipe tomat menunjukkan perbedaan yang nyata (Tabel 3). Terlihat bahwa jumlah daun genotipe Makassar $(20,00)$ berbeda tidak nyata dengan genotipe CIN $06(17,66)$ dibandingkan genotipe lainnya. Sementara, genotipe Gondol Lonjong memiliki rataan jumlah daun yang paling sedikit $(11,00)$. Jumlah daun tanaman merupakan komponen yang dapat menunjukkan pertumbuhan tanaman.

\section{Kerapatan Stomata}

Kerapatan stomata merupakan jumlah stomata per satuan luas bidang pandang tertentu (Santosa et al., 2013). Kerapatan stomata genotipe tomat tertinggi terdapat pada genotipe Makassar sebesar 271,77 $\mathrm{mm}^{2}$ dan terendah pada genotipe Lombok 4 sebesar 88,90 $\mathrm{mm}^{2}$. Penelitian Lestari (2006) menyatakan bahwa kerapatan stomata terendah sebesar $121,15 \mathrm{~mm}^{2}$ dan ter- 
Tabel 1. Hasil analisis varians untuk variabel vegetatif 16 genotipe tomat

\begin{tabular}{clcc}
\hline No & \multicolumn{1}{c}{ Variabel pengamatan } & F hitung & Probabilitas \\
\hline 1 & Tinggi tanaman & $5.82^{*}$ & 0.000 \\
2 & Diameter batang & $3.24^{*}$ & 0.002 \\
3 & Jumlah daun & $4.47^{*}$ & 0.000 \\
4 & Tingkat kehijauan daun & $0.35^{\text {th }}$ & 0.304 \\
5 & Kerapatan stomata & $8.84^{*}$ & 0.000 \\
6 & Umur berbunga & $7.53^{*}$ & 0.000 \\
\hline \multicolumn{2}{l}{ Keterangan $*^{*}=$ berbeda nyata pada uji F dengan taraf 5 \% }
\end{tabular}
$\mathrm{tn}=$ berbeda tidak nyata pada uji $\mathrm{F}$ dengan taraf $5 \%$

Tabel 2. Hasil analisis varians untuk variabel generatif 16 genotipe tomat

\begin{tabular}{clcc}
\hline No & \multicolumn{1}{c}{ Variabel pengamatan } & F hitung & Probabilitas \\
\hline 1 & Umur panen & $4.98^{*}$ & 0.000 \\
2 & Diameter buah & $3.24^{*}$ & 0.002 \\
3 & Kemanisan buah & $5.74^{*}$ & 0.000 \\
4 & Kekerasan buah & $3.14^{*}$ & 0.005 \\
5 & Bobot per buah & $0.39^{\text {th }}$ & 0.142 \\
6 & Bobot buah total per tanaman & $3.20^{*}$ & 0.004 \\
7 & Bobot segar brangkasan & $2.26^{*}$ & 0.036 \\
8 & Bobot kering brangkasan & $2.55^{*}$ & 0.019 \\
\hline \multicolumn{2}{r}{ Keterangan : * berbeda nyata pada uji F dengan taraf 5\% } \\
\multicolumn{4}{c}{ tn = berbeda tidak nyata pada uji F dengan taraf 5\% }
\end{tabular}

Tabel 3. Hasil uji lanjut terhadap tinggi tanaman, diameter batang, jumlah daun, kerapatan stomata, dan umur berbunga genotipe tomat.

\begin{tabular}{|c|c|c|c|c|c|}
\hline Genotipe & $\begin{array}{l}\text { Tinggi } \\
\text { Tanaman } \\
(\mathrm{cm})\end{array}$ & $\begin{array}{c}\text { Diameter } \\
\text { Batang } \\
(\mathrm{mm})\end{array}$ & $\begin{array}{c}\text { Jumlah } \\
\text { Daun }\end{array}$ & $\begin{array}{c}\text { Kerapatan } \\
\text { Stomata } \\
\left(\mathrm{mm}^{2}\right)\end{array}$ & $\begin{array}{c}\text { Umur } \\
\text { Berbunga } \\
\text { (hst) }\end{array}$ \\
\hline Mirah & $54.28 \mathrm{bc}$ & $7.31 \mathrm{~b}-\mathrm{d}$ & $12.66 \mathrm{de}$ & $133,32 \mathrm{c}-\mathrm{e}$ & $24.16 \mathrm{c}-\mathrm{g}$ \\
\hline Berlian & $54.96 \mathrm{bc}$ & $7.36 \mathrm{~b}-\mathrm{d}$ & $14.50 \mathrm{~b}-\mathrm{d}$ & $111.54 \mathrm{de}$ & $24.00 \mathrm{~d}-\mathrm{g}$ \\
\hline CIN 06 & $62.85 \mathrm{ab}$ & $7.48 \mathrm{~b}-\mathrm{d}$ & $17.66 \mathrm{ab}$ & $129.95 \mathrm{de}$ & $26.16 b-f$ \\
\hline SU & $33.86 \mathrm{~d}$ & $6.35 \mathrm{~d}$ & $13.16 \mathrm{de}$ & $133.04 \mathrm{c}-\mathrm{e}$ & $16.50 \mathrm{~h}$ \\
\hline Kudamati 3 & $54.81 \mathrm{bc}$ & $7.50 \mathrm{~b}-\mathrm{d}$ & $14.33 \mathrm{~cd}$ & $117.20 \mathrm{de}$ & $28.33 \mathrm{a}-\mathrm{d}$ \\
\hline Lombok 3 & $55.00 \mathrm{bc}$ & $7.83 \mathrm{bc}$ & $14.00 \mathrm{c}-\mathrm{e}$ & $122.00 \mathrm{de}$ & $25.00 \mathrm{c}-\mathrm{f}$ \\
\hline Lombok 4 & $63.23 \mathrm{ab}$ & $8.66 \mathrm{~b}$ & $14.50 \mathrm{~b}-\mathrm{d}$ & $88.90 \mathrm{e}$ & $26.66 \mathrm{~b}-\mathrm{f}$ \\
\hline Makassar & $56.85 \mathrm{bc}$ & $10.02 \mathrm{a}$ & $20.00 \mathrm{a}$ & $271.77 \mathrm{a}$ & $21.50 \mathrm{~g}$ \\
\hline Aceh 3 & $59.28 \mathrm{bc}$ & $7.42 \mathrm{~b}-\mathrm{d}$ & $12.16 \mathrm{de}$ & $120.02 \mathrm{de}$ & $31.83 \mathrm{a}$ \\
\hline Aceh 5 & $71.73 \mathrm{a}$ & $7.33 \mathrm{~b}-\mathrm{d}$ & $15.83 \mathrm{bc}$ & $113.22 \mathrm{de}$ & $27.66 \mathrm{a}-\mathrm{e}$ \\
\hline Ranti Situbondo & $54.91 \mathrm{bc}$ & $7.98 \mathrm{bc}$ & $15.00 \mathrm{~b}-\mathrm{d}$ & $185.99 \mathrm{~b}$ & $24.16 \mathrm{c}-\mathrm{g}$ \\
\hline Ranti S. Gelombang & $49.86 \mathrm{c}$ & $8.01 \mathrm{bc}$ & $16.00 \mathrm{bc}$ & $118.34 \mathrm{de}$ & $22.33 \mathrm{gf}$ \\
\hline Situbondo & $65.76 \mathrm{ab}$ & $7.34 \mathrm{~b}-\mathrm{d}$ & $15.16 \mathrm{~b}-\mathrm{d}$ & $174.95 \mathrm{bc}$ & $28.66 \mathrm{a}-\mathrm{c}$ \\
\hline Kemir & $58.83 \mathrm{bc}$ & $7.43 \mathrm{~b}-\mathrm{d}$ & $15.33 \mathrm{~b}-\mathrm{d}$ & $140.42 \mathrm{~cd}$ & $23.66 \mathrm{e}-\mathrm{g}$ \\
\hline Meranti 2 & $72.76 \mathrm{a}$ & $7.93 \mathrm{bc}$ & $12.33 \mathrm{de}$ & $95.97 \mathrm{de}$ & $30.33 \mathrm{ab}$ \\
\hline Gondol Lonjong & $64.30 \mathrm{ab}$ & $7.20 \mathrm{~cd}$ & $11.00 \mathrm{e}$ & $95.11 \mathrm{de}$ & $25.66 \mathrm{c}-\mathrm{f}$ \\
\hline
\end{tabular}


tinggi $277,42 \mathrm{~mm}^{2}$. Kerapatan stomata dapat mempengaruhi dua proses penting pada tanaman yaitu fotosintesis dan transpirasi. Ditambahkan oleh Miskin et al. (1972), tanaman yang mempunyai kerapatan stomata yang tinggi akan memiliki laju transpirasi yang lebih tinggi daripada tanaman dengan kerapatan stomata yang rendah. Hal ini sesuai dengan penelitian Gokbayrak et al. (2008) yang mengemukakan bahwa angin merupakan salah satu faktor lingkungan yang mempengaruhi kerapatan stomata. Ketika tidak ada angin, udara sekitar daun menjadi lembab sehingga mengurangi tingkat transpirasi. Selain itu faktor yang mempengaruhi kerapatan stomata adalah faktor genotipik dan fenotipik.

\section{Umur Berbunga}

Pada pengamatan umur berbunga tercepat dicapai oleh genotipe SU yang umur berbunganya 16,50 hari setelah tanam yang berbeda nyata dengan genotipe lainnya. Umur berbunga genotipe Makassar (22,33 hst) berbeda tidak nyata dengan Ranti Situbondo Gelombang (23,66 hst). Menurut Hartati (2000) dalam penelitiannya bahwa umur berbunga paling cepat adalah varietas Ratna yaitu 18,11 hari. Umur berbuah dipengaruhi oleh umur berbunga, oleh sebab itu ada kemungkinan berbunganya cepat tetapi umur berbuahnya lambat karena banyak bunga yang gugur. Umur berbunga terlama dimiliki oleh genotipe Aceh 3 (31,83 hst), Meranti 2 (30,33), Situbondo $(28,66)$, Kudamati $3(28,33)$, dan Aceh 5 $(27,66)$. Rahman et al. (2013) dalam penelitiannya mengatakan bahwa umur berbunga genotipe BINA-5 adalah 37,25 hari. Ditambahkan Narziwan et al. (2014) dalam penelitiannya menunjukkan seluruh galur tomat lokal memiliki umur berbunga 28-31 hst. Perbedaan umur berbunga pada tiap tanaman dapat terjadi akibat pengaruh suhu, cahaya dan unsur hara yang diserap oleh tanaman (Arnanto et al., 2013).

\section{Pertumbuhan Generatif Genotipe Tomat}

Variabel pengamatan generatif genotipe tomat yang berbeda nyata dilakukan uji lanjut menggunakan Duncan's Multiple Range Test (DMRT) pada taraf $5 \%$, yang disajikan pada Tabel 4.

\section{Umur Panen}

Genotipe yang memilki umur panen paling lama yaitu genotipe Aceh 3 dengan umur panen $(66,50 \mathrm{hst})$ yang berbeda tidak nyata dengan Meranti 2 (64,00 hst), Situbondo (64,00 hst), Aceh 5 (62,16 hst), Lombok 3 (60,66 hst), CIN 06 (58,83 hst), dan Berlian (58,50 hst). Sedangkan genotipe yang memiliki umur panen paling cepat terdapat pada genotipe SU dengan umur panen 46,16 hst. Penelitian Pongoh (2011) mengatakan bahwa penampilan umur panen varietas tomat yaitu $61,6-70,6$ hst. Sementara penelitian Koesriharti et al. (2012) terhadap tomat yang diteliti menunjukkan umur panen 66-70 hst.

\section{Diameter Buah}

Dalam pengujian ini, diameter buah genotipe paling kecil terdapat pada genotipe Ranti Situbondo dengan nilai 10,62 $\mathrm{mm}$ yang berbeda nyata dengan genotipe lainnya. Sedangkan genotipe yang memiliki diameter buah terbesar terdapat pada genotipe Berlian (45,15 mm) yang berbeda tidak nyata dengan Makassar (37,69 mm), Situbondo $(35,98 \mathrm{~mm})$, Lombok 4 (34,09 $\mathrm{mm})$, Ranti S. Gelombang (29,51 mm), Aceh $5(28,88 \mathrm{~mm})$, Kudamati $3(27,19$ $\mathrm{mm}), \operatorname{CIN}(27,06 \mathrm{~mm})$, Kemir (26,70 mm), Lombok 3 (26,52 mm), dan Gondol Lonjong $(26,40 \mathrm{~mm})$. Berdasarkan hasil penelitian Suryadi et al. (2004) tomat yang ditelitinya mempunyai diameter buah dengan ukuran 4,7-5,3 cm sedangkan hasil penelitian Situmorang et al. (2014) mengatakan bahwa genotipe IPB T34-7-7 mempunyai diameter yang paling besar yaitu $3,42 \mathrm{~cm}$ 
Tabel 4. Hasil uji lanjut terhadap umur panen, diameter buah, kemanisan buah, kekerasan buah, bobot buah total, bobot segar brangkasan dan bobot kering brangkasan genotipe tomat

\begin{tabular}{lccccccc}
\hline Genotipe & $\begin{array}{c}\text { Umur } \\
\text { Panen (hst) }\end{array}$ & $\begin{array}{c}\text { Diameter } \\
\text { Buah }(\mathrm{mm})\end{array}$ & $\begin{array}{c}\text { Kemanisan } \\
\text { Buah (brix) }\end{array}$ & $\begin{array}{c}\text { Kekerasan } \\
\text { Buah } \\
\left(\mathrm{kgf} / \mathrm{cm}^{2}\right)\end{array}$ & $\begin{array}{c}\text { Bobot } \\
\text { Buah Total } \\
(\mathrm{g})\end{array}$ & $\begin{array}{c}\text { Bobot Segar } \\
\text { Brangkasan } \\
(\mathrm{g})\end{array}$ & $\begin{array}{c}\text { Bobot Kering } \\
\text { Brangkasan } \\
(\mathrm{g})\end{array}$ \\
\hline Mirah & $66.50 \mathrm{a}$ & $20.24 \mathrm{bc}$ & $5.11 \mathrm{c}-\mathrm{f}$ & $1.66 \mathrm{a}-\mathrm{e}$ & $116.3 \mathrm{~cd}$ & $99.96 \mathrm{bc}$ & $21.25 \mathrm{~b}-\mathrm{d}$ \\
Berlian & $58.50 \mathrm{a}-\mathrm{d}$ & $45.15 \mathrm{a}$ & $4.33 \mathrm{fg}$ & $1.51 \mathrm{~b}-\mathrm{e}$ & $325.6 \mathrm{~b}-\mathrm{d}$ & $112.20 \mathrm{bc}$ & $20.76 \mathrm{~cd}$ \\
CIN 06 & $58.83 \mathrm{a}-\mathrm{d}$ & $27.06 \mathrm{a}-\mathrm{c}$ & $6.22 \mathrm{a}-\mathrm{c}$ & $1.65 \mathrm{a}-\mathrm{e}$ & $249.9 \mathrm{~b}-\mathrm{d}$ & $172.03 \mathrm{a}-\mathrm{c}$ & $26.48 \mathrm{a}-\mathrm{d}$ \\
SU & $46.16 \mathrm{f}$ & $19.88 \mathrm{bc}$ & $4.27 \mathrm{fg}$ & $1.41 \mathrm{c}-\mathrm{e}$ & $394.3 \mathrm{~b}-\mathrm{d}$ & $84.45 \mathrm{c}$ & $14.02 \mathrm{~cd}$ \\
Kudamati 3 & $58.16 \mathrm{~b}-\mathrm{d}$ & $27.19 \mathrm{a}-\mathrm{c}$ & $4.83 \mathrm{~d}-\mathrm{g}$ & $1.79 \mathrm{a}-\mathrm{c}$ & $468.7 \mathrm{ab}$ & $137.00 \mathrm{a}-\mathrm{c}$ & $22.21 \mathrm{~b}-\mathrm{d}$ \\
Lombok 3 & $60.66 \mathrm{a}-\mathrm{c}$ & $26.52 \mathrm{a}-\mathrm{c}$ & $5.38 \mathrm{~b}-\mathrm{f}$ & $1.76 \mathrm{a}-\mathrm{c}$ & $300.7 \mathrm{~b}-\mathrm{d}$ & $111.10 \mathrm{bc}$ & $22.56 \mathrm{~b}-\mathrm{d}$ \\
Lombok 4 & $55.50 \mathrm{c}-\mathrm{e}$ & $34.09 \mathrm{ab}$ & $6.20 \mathrm{a}-\mathrm{d}$ & $1.73 \mathrm{a}-\mathrm{d}$ & $274.8 \mathrm{~b}-\mathrm{d}$ & $234.52 \mathrm{a}$ & $39.03 \mathrm{ab}$ \\
Makassar & $50.00 \mathrm{ef}$ & $37.69 \mathrm{ab}$ & $4.66 \mathrm{e}-\mathrm{g}$ & $1.51 \mathrm{~b}-\mathrm{e}$ & $743.9 \mathrm{a}$ & $200.80 \mathrm{ab}$ & $35.07 \mathrm{a}-\mathrm{c}$ \\
Aceh 3 & $66.50 \mathrm{a}$ & $22.27 \mathrm{bc}$ & $7.25 \mathrm{a}$ & $1.75 \mathrm{a}-\mathrm{d}$ & $68.1 \mathrm{~d}$ & $158.60 \mathrm{a}-\mathrm{c}$ & $43.00 \mathrm{a}$ \\
Aceh 5 & $62.16 \mathrm{a}-\mathrm{c}$ & $28.88 \mathrm{a}-\mathrm{c}$ & $5.72 \mathrm{~b}-\mathrm{e}$ & $1.871 \mathrm{~b}$ & $273.3 \mathrm{~b}-\mathrm{d}$ & $102.08 \mathrm{bc}$ & $19.40 \mathrm{~cd}$ \\
Ranti Situbondo & $56.25 \mathrm{~b}-\mathrm{e}$ & $10.62 \mathrm{c}$ & $5.33 \mathrm{~b}-\mathrm{f}$ & $1.51 \mathrm{~b}-\mathrm{e}$ & $76.6 \mathrm{~d}$ & $88.50 \mathrm{c}$ & $23.21 \mathrm{~b}-\mathrm{d}$ \\
Ranti S. Gelombang & $51.50 \mathrm{~d}-\mathrm{f}$ & $29.51 \mathrm{a}-\mathrm{c}$ & $4.22 \mathrm{fg}$ & $1.36 \mathrm{de}$ & $461.7 \mathrm{a}-\mathrm{c}$ & $156.85 \mathrm{a}-\mathrm{c}$ & $29.26 \mathrm{a}-\mathrm{d}$ \\
Situbondo & $64.00 \mathrm{ab}$ & $35.98 \mathrm{ab}$ & $6.05 \mathrm{a}-\mathrm{d}$ & $1,79 \mathrm{a}-\mathrm{c}$ & $512.7 \mathrm{ab}$ & $174.82 \mathrm{a}-\mathrm{c}$ & $35.20 \mathrm{a}-\mathrm{d}$ \\
Kemir & $56.66 \mathrm{~b}-\mathrm{e}$ & $26.70 \mathrm{a}-\mathrm{c}$ & $3.89 \mathrm{~g}$ & $1.34 \mathrm{e}$ & $363.5 \mathrm{~b}-\mathrm{d}$ & $131.67 \mathrm{a}-\mathrm{c}$ & $19.62 \mathrm{~cd}$ \\
Meranti 2 & $64.00 \mathrm{ab}$ & $22.71 \mathrm{bc}$ & $6.66 \mathrm{ab}$ & $1.93 \mathrm{a}$ & $75.0 \mathrm{~d}$ & $124.65 \mathrm{bc}$ & $18.80 \mathrm{~cd}$ \\
Gondol Lonjong & $57.00 \mathrm{~b}-\mathrm{e}$ & $26.40 \mathrm{a}-\mathrm{c}$ & $5.00 \mathrm{c}-\mathrm{g}$ & $1.91 \mathrm{a}$ & $76.9 \mathrm{~d}$ & $103.04 \mathrm{bc}$ & $17.10 \mathrm{~cd}$ \\
\hline Keterangan : Angka yang dikuti oleh huruf yang sama pada kolom yang sama berbeda tidak nyata pada uji DMRT
\end{tabular}

dan genotipe IPB T53-3-3 memiliki diameter yang paling kecil yaitu $2,38 \mathrm{~cm}$.

\section{Kemanisan Buah}

Kandungan kemanisan buah dari setiap genotipe yang diteliti memiliki nilai yang berkisar dari 3,89 sampai 7,25 brix. Menurut Hayati (2014) bahwa kandungan kemanisan buah terlarut dari setiap genotipe yang diteliti memiliki nilai yang berkisar dari 4 sampai 8 brix. Kandungan kemanisan buah paling tinggi terdapat pada genotipe Aceh 3 yang berbeda tidak nyata dengan Meranti 2, CIN 06 , dan Lombok 4. Berdasarkan penelitian Fardhani et al. (2013) bahwa kandungan kemanisan buah tertinggi terdapat pada galur G60 bernilai 6,63 brix.

\section{Kekerasan Buah}

Kekerasan buah merupakan komponen mutu buah yang banyak menjadi pertimbangan konsumen dalam memilih buah tomat setelah melihat penampilan bagian luar buah (Ambarwati et al., 2009). Kekerasan buah yang diuji antar genotipe memiliki nilai yang bervariasi berkisar
$1,34-1,93 \mathrm{kgf} / \mathrm{cm}^{2}$. Semakin besar angka penetrometer yang dihasilkan maka tingkat kekerasan buah semakin tinggi, dalam hal ini genotipe Meranti 2 memiliki daya simpan paling lama dengan nilai $1,93 \mathrm{kgf} /$ $\mathrm{cm}^{2}$ dan Gondol Lonjong dengan nilai 1,91 $\mathrm{kgf} / \mathrm{cm}^{2}$. Menurut Wijayani dan Widodo (2005) kekerasan buah tomat sangat terkait erat dengan kadar air yang dikandung buah tersebut. Apabila kadar airnya tinggi maka buah tersebut akan lembek atau berkurang kekerasannya, sebaliknya apabila kadar airnya sedikit maka buah akan menunjukkan kekerasan yang lebih tinggi apabila diukur dengan alat penetrometer $1 \mathrm{~kg}$. Hal yang sama diungkapkan oleh Roiyana et al. (2012) bahwa semakin matang tomat yang digunakan akan mempunyai nilai kekerasan (tekstur) yang lebih rendah, hal ini disebabkan karena adanya perubahan yang terjadi pada dinding sel yaitu larutnya pektin dan depolimerisasi substansi pektin.

\section{Bobot Buah Total}

Bobot buah total dipengaruhi oleh besar buah. Dari seluruh tomat yang diuji genotipe Makassar memiliki bobot buah 
total per tanaman tertinggi yaitu 743,9 g dan berbeda tidak nyata dengan Situbondo (512,7 g), Kudamati 3 (468,7 g), dan Ranti S. Gelombang (461,7 g). Sementara, genotipe Gondol Lonjong (76,9 g) berbeda tidak nyata dengan Ranti Situbondo (76,6 g), Meranti 2 (75,0 g), dan Aceh 3 (68,1 g) yang memiliki bobot buah total terendah. Kusandrayani et al. (2005) dalam penelitiannya mengatakan bahwa bobot buah total tertinggi ditunjukkan oleh nomor LV-4481 yaitu $730 \mathrm{~g}$ dan terendah ditunjukkan oleh nomor LV-2261 sebesar 75 g. Perbedaan bobot buah disebabkan oleh interaksi antara faktor genotipe dan lingkungan (Suryadi et al., 2004).

\section{Bobot Segar Brangkasan}

Genotipe Lombok 4 memiliki bobot segar brangkasan tertinggi yang berbeda tidak nyata dengan Makassar, Situbondo, CIN 06, Aceh 3, Ranti S. Gelombang, Kudamati 3, dan Kemir kecuali Ranti Situbondo dan Gondol Lonjong. Bobot segar brangkasan yang rendah cenderung memiliki bobot buah yang rendah (Tabel 4). Menurut Lahadassy et al. (2007) untuk mencapai bobot segar optimal, tanaman membutuhkan energi dan unsur hara yang mencukupi yang digunakan untuk meningkatkan jumlah maupun ukuran sel serta mempengaruhi terhadap kecukupan kebutuhan air.

\section{Bobot Kering Brangkasan}

Bobot kering genotipe Aceh 3 memiliki bobot kering brangkasan tertinggi yang berbeda tidak nyata dengan Lombok 4, Situbondo, Makassar, Ranti S. Gelombang, CIN 06 dibandingkan genotipe lainnya. Bobot kering brangkasan dipengaruhi oleh akar, batang, dan daun tanaman tomat. Bobot kering tanaman mencerminkan pola tanaman mengakumulasikan produk dari proses fotosintesis dan merupakan interaksi dengan faktor lingkungan.

\section{KESIMPULAN DAN SARAN}

\section{Kesimpulan}

1. Dari 16 genotipe tomat yang diteliti, masing-masing genotipe memiliki perbedaan

2. pada tinggi tanaman, diameter batang, jumlah daun, kerapatan stomata, umur berbunga, umur panen, diameter buah, kemanisan buah, kekerasan buah, bobot buah total, bobot segar brangkasan, dan bobot kering brangkasan.

3. Berdasarkan bobot buah total genotipe yang berpotensi dibudidayakan di dataran rendah adalah Ranti S. Gelombang, Kudamati 3, Situbondo, dan Makassar.

\section{Saran}

Penelitian ini perlu diuji pada ketinggian tempat yang berbeda agar hasil produksinya lebih baik dan dapat dijadikan sebagai bahan genetik pemuliaan untuk menghasilkan varietas unggul.

\section{DAFTAR PUSTAKA}

Ambarwati, E., R.H. Murti, S. Trisnowati. 2009. Perakitan Tomat Berproduksi Tinggi untuk Dataran Tinggi dan Dataran Rendah. Laporan Penelitian. Fakultas Pertanian Universitas Gadjah Mada. Yogyakarta.

Arnanto, D., N.Basuki dan Respatijarti. 2013. Uji toleransi salinitas terhadap sepuluh genotip F1 tomat (Solanum lycopersicum L.). Jurnal Produksi Tanaman 1(5):415-421.

Badan Pusat Statistik. 2012. Produksi sayuran di Indonesia. http://www.bps. go.id. Diakses 24 April 2014.

Cahyono, B. 2008. Tomat Usaha Tani dan Penanganan Pascapanen. Kanisius. Yogyakarta. 
Fardhani, A., E. Ambarwati., S.Trisnowati dan Rudi. 2013. Potensi hasil, mutu dan daya simpan buah enam galur mutan harapan tomat (Solanum lycopersicum L.). Jurnal Vegetalika 2(4):88-100.

Fitriani, E. 2012. Untung Berlipat Budidaya Tomat di Berbagai Media Tanam. Pustaka Baru Press, Yogyakarta.

Gokbayrak, Z., A. Dardeniz and M. Bal. 2008. Stomatal density adaptation of grapevine to windy conditions. Trakia Journal of Sciences 6(1):18-22 .

Hartati, S.2000. Penampilan genotip tanaman tomat (Lycopersicum esculentum Mill.). Jurnal Agrosains. 2(2):35-42.

Hayati, D. 2014. Karakterisasi morfologi dan fisiologi 15 genotipe tomat (Solanum lycopersicum L.). Skripsi. Universitas Bengkulu, Bengkulu (tidak dipublikasikan).

Jones, B. 2008. Tomato Plant Culture. In the field, Greenhouse and Home Garden. CRC Press, New York.

Koesriharti., H. Ninuk and Syamira. 2012. Effect of water management on yield of tomato plant (Lycopersicon esculentum Mill). Journal of Agriculture and Food Technology. 2(1):16-20.

Kusandryani, Y., Luthfy dan Gunawan. 2005. Karakterisasi dan deskripsi plasma nutfah tomat. Jurnal Buletin plasma Nutfah 11(2):55-59.

Lahadassy,J., Mulyati dan Sanaba. 2007. Pengaruh konsentrasi pupuk organik padat daun gamal terhadap tanaman sawi. Jurnal Agrisistem 2(3):80-89.

Lestari, E.G. 2006. Hubungan antara kerapatan stomata dengan ketahanan kekeringan pada somaklon padi gajahmungkur, towuti dan IR 64. Jurnal Biodiversitas 7(1):44-48.
Miskin, K.E., D.C. Rasmusson and D.N. Moss. 1972. Inheritance and physiological effects of stomatal frequency in barley. Journal of Crop Science 12(6):780-783.

Nazirwan., A. Wahyudi dan Dulbari. 2014. Karakterisasi koleksi plasma nutfah tomat lokal dan introduksi. Jurnal Penelitian Pertanian Terapan 14(1):70-75.

Pongoh, J. 2011. Penampilan beberapa varietas tomat pada dua kondisi lingkungan. Jurnal Eugenia 17(2):142-149.

Prihantoko, E. 2006. Penggunaan isolat bakteri tanah untuk pengendalian hayati Rhizoctonia solani penyebab busuk kecambah pada tanaman tomat. Skripsi. Fakultas Matematika dan Ilmu Pengetahuan Alam. Institut Pertanian Bogor, Bogor (dipublikasikan).

Purwati, E. 2007. Perbaikan Mutu Tomat Varietas Kaliurang. Balai Penelitian Tanaman Sayuran. Jurnal Agrivigor 6(3):270-275.

Purwati, E. 2009. Daya hasil tomat hibrida (F1) di dataran medium. Balai Penelitian Tanaman Sayuran. Jurnal Hortikultura 15(2):125-130

Rahman, M.H., M.A. Khan and Islam. 2013. Effect of ABT-6 hormone on growth and yield of BINA tomato-5. Journal of Natural Products 6:103-108.

Roiyana, M., M. Izzati dan Erma. 2012. Potensi dan efisiensi senyawa hidrokoloid nabati sebagai bahan penunda pematangan buah. Jurnal Buletin Anatomi dan Fisiologi 20(2):40-50.

Santosa, B., K.R.Trijatmiko dan T.J.Santosa. 2013. Deteksi gen hpll dan keragaan agronomis pada populasi $\mathrm{BC}_{1} \mathrm{~F}_{1}$ tanaman padi transgenik. Jurnal Agrobiogen $9(3): 117-124$. 
Situmorang, A., Adiwirman dan Deviona. 2014. Uji pertumbuhan dan daya hasil enam genotipe tomat (Lycopersicum esculentum Mill) di dataran rendah. Skripsi. Universitas Riau, Riau (tidak dipublikasikan).

Suryadi., Luthfy., K. Yenny dan Gunawan. 2004. Karakterisasi koleksi plasma nutfah tomat lokal dan introduksi. Jurnal Buletin Plasma Nutfah. 10(2):72-76.

Sutapradja, H. 2008. Pertumbuhan dan hasil tanaman tomat kultivar intan dan mutiara pada berbagai jenis tanah. Jurnal Hortikultura 8(2):160-164.

Villareal, R.L. 1980. Tomato in the tropics. Westview Press, Colorado.
Wasonawati, C. 2011. Meningkatkan pertumbuhan tanaman tomat (Lycopersicon esculentum Mill) dengan sistem budidaya hidroponik. Jurnal Agrovigor 4(1):21-28.

Widiyastiningsih., Sakhidin dan Supartoto. 2012. Respon beberapa varietas tomat (Lycopersicum esculentum Mill) terhadap pemberian mikoriza dan EM4. jos.unsoed.ac.id/index.php/ jinta/article/download/359/177. Diakses 8 Agustus 2014.

Wijayani, A., dan W. Widodo. 2005. Usaha meningkatkan beberapa kualitas tomat dengan sistem budidaya hidroponik. Jurnal Ilmu pertanian 12(1):77-83. 